\title{
Ischemia/Reperfusion Injury in Liver Surgery and Transplantation: Pathophysiology
}

\author{
Kilian Weigand, ${ }^{1}$ Sylvia Brost, ${ }^{1}$ Niels Steinebrunner, ${ }^{2}$ Markus Büchler, ${ }^{3}$ \\ Peter Schemmer, ${ }^{3}$ and Martina Müller ${ }^{1}$ \\ ${ }^{1}$ Department of Gastroenterology, Endocrinology, Rheumatology and Infectious Diseases, \\ University Hospital Regensburg, D-93053 Regensburg, Germany \\ ${ }^{2}$ Department of Gastroenterology, University Hospital Heidelberg, D-69120 Heidelberg, Germany \\ ${ }^{3}$ Department of General and Transplant Surgery, University Hospital Heidelberg, D-69120 Heidelberg, Germany
}

Correspondence should be addressed to Kilian Weigand, kilian.weigand@ukr.de

Received 18 February 2012; Accepted 5 April 2012

Academic Editor: John J. Lemasters

Copyright (๑) 2012 Kilian Weigand et al. This is an open access article distributed under the Creative Commons Attribution License, which permits unrestricted use, distribution, and reproduction in any medium, provided the original work is properly cited.

\begin{abstract}
Liver ischemia/reperfusion (IR) injury is caused by a heavily toothed network of interactions of cells of the immune system, cytokine production, and reduced microcirculatory blood flow in the liver. These complex networks are further elaborated by multiple intracellular pathways activated by cytokines, chemokines, and danger-associated molecular patterns. Furthermore, intracellular ionic disturbances and especially mitochondrial disorders play an important role leading to apoptosis and necrosis of hepatocytes in IR injury. Overall, enhanced production of reactive oxygen species, found very early in IR injury, plays an important role in liver tissue damage at several points within these complex networks. Many contributors to IR injury are only incompletely understood so far. This paper tempts to give an overview of the different mechanisms involved in the formation of IR injury. Only by further elucidation of these complex mechanisms IR injury can be understood and possible therapeutic strategies can be improved or be developed.
\end{abstract}

\section{Introduction}

Ischemia/reperfusion (IR) injury of the liver results from a loss of blood supply reducing oxygen supply to the organ. Upon revascularisation the liver undergoes reperfusion injury. Together these factors lead to affection of oxygendependent cells within the liver causing impairment of organ function. Affected are all cells requiring mitochondrial oxidative phosphorylation for their metabolism [1]. Warm IR injury can be separated from cold IR injury. Warm IR injury occurs during prolonged surgical liver resection using clamping of the perfusion [2]. Other aetiologies are reduced liver perfusion due to shock, heart failure, respiratory failure, hemorrhage, trauma, and sepsis [3-5]. In contrast, cold IR injury follows liver transplantation with the necessity of cold preservation of the donor organ, followed by reperfusion after implantation $[6,7]$. Furthermore, it has been demonstrated that tissue damage occurs in two phases, an early and a late phase $[8,9]$. The early phase which occurs within the first 6 hours following reperfusion is thought to be the consequence of the fast change in the redox state of the liver tissue $[9,10]$. Most likely, this change is caused by hepatocytes, Kupffer cells (KCs), and sinusoidal endothelial cells (SECs) $[8,9,11]$. In contrast, the late phase of IR injury is caused by the production of cytokines and chemokines followed by the infiltration of leukocytes into the liver tissue $[8,9,12]$.

Of clinical relevance is that liver IR injury results in elevated liver enzymes, biliary strictures, clinical dysfunction, or even liver failure [13]. Furthermore, other organs can develop dysfunction secondary to the liver damage. Possible affected organs are lungs, heart, kidneys, and blood vessels [14-17]. Risk factors for IR injury include age of the liver, sex and others [18-21].

A complex network and cross talk of multiple molecular mechanisms and cellular interactions lead to liver IR injury $[22,23]$. The result of these processes is cell death by apoptosis and necrosis via different pathways. Redox status, 
cellular ionic disturbances, cytokines, chemokines, other mediators and molecular mechanisms as well as many different cells like KC, SEC, dendritic cells, leukocytes, and lymphocytes are involved in this process and are closely interlocked. Therefore, there are still many open questions regarding this inflammatory response. This paper tempts to give a systematic overview of the different components and signalling pathways leading to IR injury.

\section{Altered Redox Status and Reduced Microcirculatory Blood Flow}

IR injury starts with reduced blood flow and a lack of oxygen supply $[24,25]$. This ischemia leads to a lack of adenosine triphosphate (ATP) production in hepatocytes, $\mathrm{KC}$, and SEC [26]. As a result the function of the ATPdependent sodium/potassium plasma membrane pump $\left(\mathrm{Na}^{+} / \mathrm{K}^{+}\right.$ATPase) is impaired. This results in an increase of intracellular $\mathrm{Na}^{+}$, which is followed by a swelling of the hepatocytes, KC and SEC. Narrowing of the sinusoidals is the consequence. Within minutes after reperfusion, enhanced levels of reactive oxygen species (ROS), such as superoxide $\left(\mathrm{O}_{2}{ }^{-}\right)$, hydrogen peroxide $\left(\mathrm{H}_{2} \mathrm{O}_{2}\right)$ and hydroxyl radical $\left(\mathrm{OH}^{\bullet}\right)$, can be measured $[8,9,11,27]$. Cellular sources for these ROS are mitochondrial metabolism, hepatocytederived xanthine oxidase, and $\mathrm{KC}$ - and SEC-associated NADPH oxidase $[8,9,11,28]$. This increase of ROS is accompanied by reduced nitric oxide (NO), most likely due to a decreased function of the NO synthase (NOS) in SEC [29, 30]. Since NO is a vasodilator [31], reduced NO aggravates the sinusoidal narrowing. However, these mechanisms are still controversially discussed [32, 33]. Especially the role of the different NOS isoforms is still unclear [34]. The effects of $\mathrm{NO}$ are well known. It increases the sinusoidal diameter and increases intrahepatic ATP levels via better oxygen supply. Thereby mitochondrial damage and leukocyte infiltration are reduced. Since NO is synthesized by NOS, NOS should be protective in IR injury. While this is well observed for the endothelial NOS (eNOS), the role of the inducible NOS (iNOS) is less clear [34]. In the late phase of IR injury it probably is also protective, while in the early phase, there may be a harmful role of iNOS.

Nevertheless, the changes occurring in IR injury lead to a more oxidative environment with the ROS leading to both, apoptotic and necrotic cell death of hepatocytes and SEC $[35,36]$. ROS causes damage to membrane lipids resulting in cell swelling and death [35]. The damage is not limited to the plasma membrane but includes cell organelles and extracellular matrix. Besides swelling of cells and reduced NO levels, the described damage leads to an increase of vasoconstrictors like endothelin and thromboxane A2 [37]. In addition, adhesion and aggregation of platelets and leucocytes is increased (see below). This leads to further narrowing of the sinusoidals with significant reduction of microcirculatory blood flow including areas with complete absence of blood flow [38], enhancing the lack of oxygen supply. Increased ROS and decreased NO levels play further roles which will be discussed below.

\section{Ionic and Mitochondrial Disturbances}

In IR injury significant changes of intracellular $\mathrm{Ca}^{2+}$ concentration in the hepatocytes can be found [39]. $\mathrm{Ca}^{2+}$ is mainly found in three cellular compartments, in the cytosol, the mitochondria, and the endoplasmic reticulum (ER). The homeostatic concentration is regulated by different $\mathrm{Ca}^{2+}$ channels. In IR injury cytosolic $\mathrm{Ca}^{2+}$ concentration is increased as a result of increased entry across the plasma membrane and release from the ER. Reason for this cytoplasmic $\mathrm{Ca}^{2+}$ overload is the activation of the ryanodine receptor in the ER membrane and the so-called transient receptor potential (TRP) channels in the plasma membrane. There is evidence that ROS can activate these channels [40, 41]. Secondary to decreased $\mathrm{Ca}^{2+}$ concentration in the endoplasmic reticulum so-called store operated calcium (SOC) channels in the plasma membrane further increase $\mathrm{Ca}^{2+}$ influx [42, 43]. In addition, in IR injury the $\mathrm{Ca}^{2+}$ ATPase in ER and plasma membrane is inhibited, potentially because of ATP depletion. Normally this $\mathrm{Ca}^{2+}$ ATPase discharges cytosolic $\mathrm{Ca}^{2+}$ into extracellular space and into the ER counteracting the above mentioned $\mathrm{Ca}^{2+}$ channels [44].

Increased cytosolic $\mathrm{Ca}^{2+}$ leads to stimulation of the $\mathrm{Ca}^{2+}$ uniporter in the mitochondrial membrane [45]. As a result the mitochondrial $\mathrm{Ca}^{2+}$ concentration increases as well. The mechanism how the mitochondrial $\mathrm{Ca}^{2+}$ uniporter is activated has not been fully resolved, so far. It is believed that the mitochondrial $\mathrm{P} 2 \mathrm{Y}$-like receptor $1\left(\mathrm{mP} 2 \mathrm{Y}_{1}\right)$ is activated by adenosine diphosphate (ADP) and adenosine monophosphate (AMP). The $\mathrm{mP}_{2} \mathrm{Y}_{1}$ stimulates the PLCdependent $\mathrm{mP} 2 \mathrm{Y}$-like receptor resulting in activation of the $\mathrm{Ca}^{2+}$ uniporter $[46,47]$. In contrast, $\mathrm{mP}_{2} \mathrm{Y}_{2}$ activated by ATP leads to inhibition of the uniporter. During IR injury ATP is depleted, as discussed before, possibly leading to activation of the uniporter. As a consequence of this increased mitochondrial $\mathrm{Ca}^{2+}$ concentration the mitochondrial transmembrane potential is reduced. To maintain the mitochondrial membrane the mitochondrial ATP-synthase reverses its activity and hydrolyzes ATP to provide energy for different ionic pumps in the mitochondrial membrane [39]. However, this further increases $\mathrm{Ca}^{2+}$ influx resulting in ATP consumption instead of production in the mitochondria. This is enhanced by the fact that ROS causes oxidative damage to the enzymes of the respiratory chain in the mitochondria leading to failure of ATP production [48]. Cytosolic and mitochondrial $\mathrm{Ca}^{2+}$ and other ionic disturbance lead to damage of plasma and mitochondrial membranes including the formation and opening of mitochondrial permeability transition (MPT) pores [49]. MPT pores are formed from integral not fully identified mitochondrial membrane proteins $[50,51]$. Hepatic mitochondria afflicted by MPT pores are permanently damaged due to depolarization of the mitochondria [37]. When only a few mitochondria are afflicted, they are removed from the hepatocyte by lysosomal mitophagy [52]. Such damaged mitochondria are a source for further ROS 


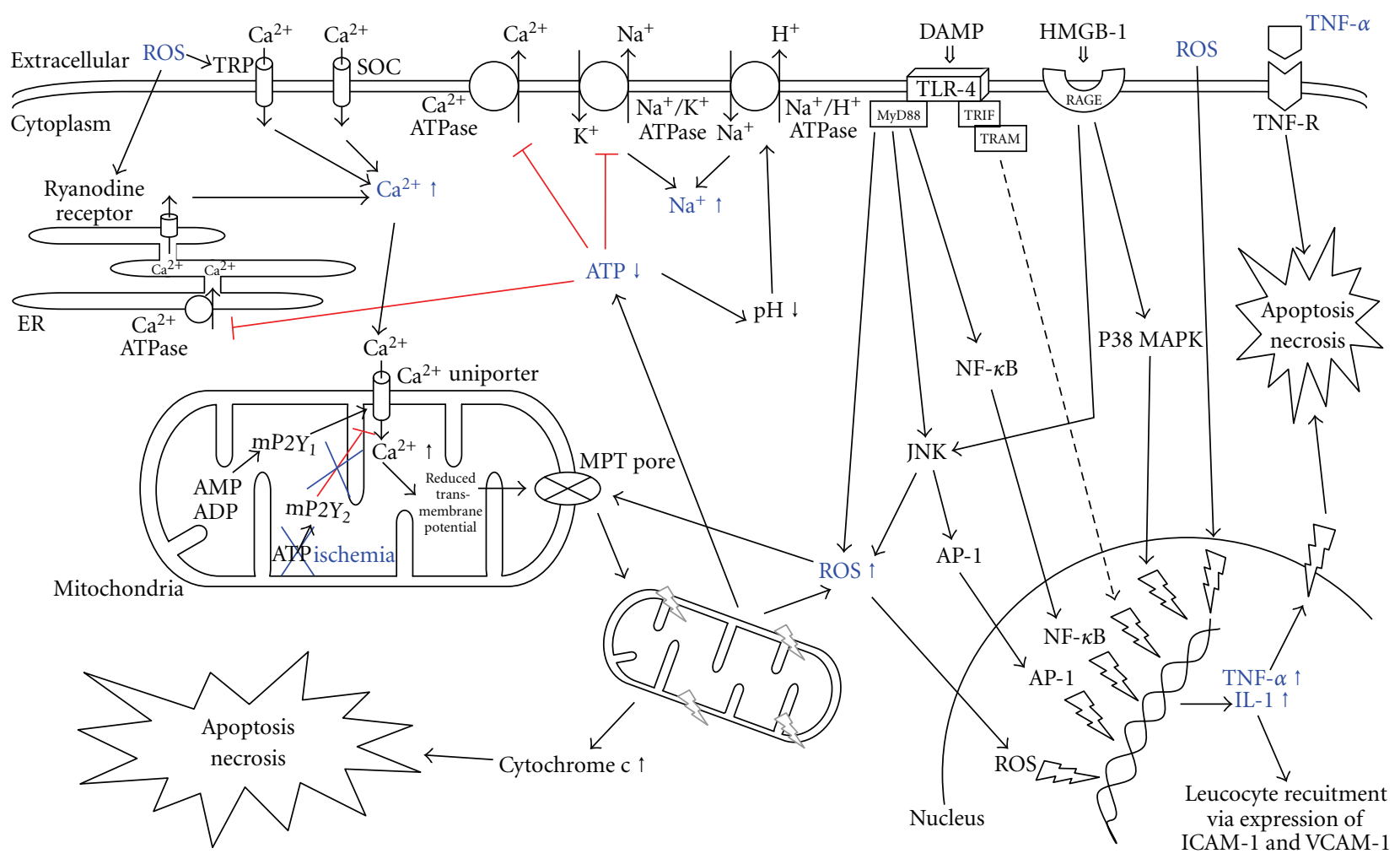

FIGURE 1: Intracellular signalling pathways and ionic disturbances engaged during IR injury, resulting in cellular swelling, apoptosis, and necrosis. ADP: adenosine diphosphate; AMP: adenosine monophosphate; AP-1: activator protein-1; ATP: adenosine triphosphate; DAMP: danger-associated molecular pattern; HMGB-1: high mobility group box-1; ICAM-1: intercellular adhesion molecule-1; IL-1: interleukin-1; JNK: c-Jun N-terminal kinase; MAPK: mitogen-activated protein kinase; MPT pore: mitochondrial permeability transition pore; MyD88: myeloid differentiation factor 88 ; NF- $\kappa$ B: nuclear factor kappa B; RAGE: receptor for advanced gylcation end product; ROS: reactive oxygen species; SOC: store operated calcium channel; TLR: toll-like receptor; TNF: tumor necrosis factor; TRAM: TRIF-related adaptor molecule; TRIF: TIR domain-containing adaptor inducing interferon; TRP: transient receptor protein; VCAM-1: vascular adhesion molecule-1.

production and ATP consumption [53]. However, ROS themselves induce MPT pore opening. With the number of damaged mitochondria increasing, cytochrome $\mathrm{C}$ is released from the mitochondria into the cytosol triggering apoptosis [48]. When the majority of the mitochondria within the hepatocyte are afflicted by MPT pores ATP levels drop too fast resulting in cell death by necrosis $[49,54]$.

Other important ionic disturbances in IR injury include intracellular $\mathrm{Na}^{+}$and hydrogen $\left(\mathrm{H}^{+}\right)$concentrations. Lack of oxygen supply leads to anaerobic respiration of the hepatocytes resulting in intracellular acidosis [55]. To stabilize intracellular $\mathrm{pH}$ within normal range the $\mathrm{Na}^{+} / \mathrm{H}^{+}$exchanger is activated by the hepatocytes, resulting in reduced cytosolic $\mathrm{H}^{+}$and further increased $\mathrm{Na}^{+}$levels. In addition, the $\mathrm{Na}^{+} / \mathrm{K}^{+}$ exchanger is ATP dependent, so ATP depletion, as in IR injury, subsequently blocks this exchange leading to further increase of intracellular $\mathrm{Na}^{+}$concentration resulting in cell death [56].

Furthermore, this counteracts the protective effect of an acidic $\mathrm{pH}$ during reperfusion [57], for example, the maintenance of an acidic $\mathrm{pH}$ prevents the formation of MPT pores [49]. However, these regulations are still based on experimental observations and need to be studied further to understand the relevance in IR injury (Figure 1).

\section{Cellular Cascade in IR Injury}

Many different cell types are involved in the process of hepatic damage and cell death in IR injury. The key cells initiating IR injury are the KCs [58-60]. Besides their direct damage by ROS, as discussed above, they are also activated by ROS leading to production of more ROS and thereby entering a cycle of self-activation and -destruction. In addition, KC are activated by the systemic complement system [61] which may also be liberated by damaged hepatocytes. In addition, complement leads to further liver damage by formation of a membrane attack complex in the plasma membrane, lysing liver cells [62].

Activated KCs also produce proinflammatory cytokines including interleukin- $1 \beta$ (IL- $1 \beta$ ) and tumor necrosis factor- $\alpha$ $(\mathrm{TNF}-\alpha)$ [63]. These cytokines lead to activation and migration of neutrophils and CD4+ T lymphocytes into the liver [64]. Furthermore, these cytokines stimulate SEC and hepatocytes to produce ROS and to express adhesion molecules on the cell surface [65]. As described above, this leads to adhesion and aggregation of leucocytes and platelets [66], influencing the microcirculatory blood flow in the liver.

The recruitment of neutrophils and CD4+ T lymphocytes is further enhanced by the matrix metalloproteinase 


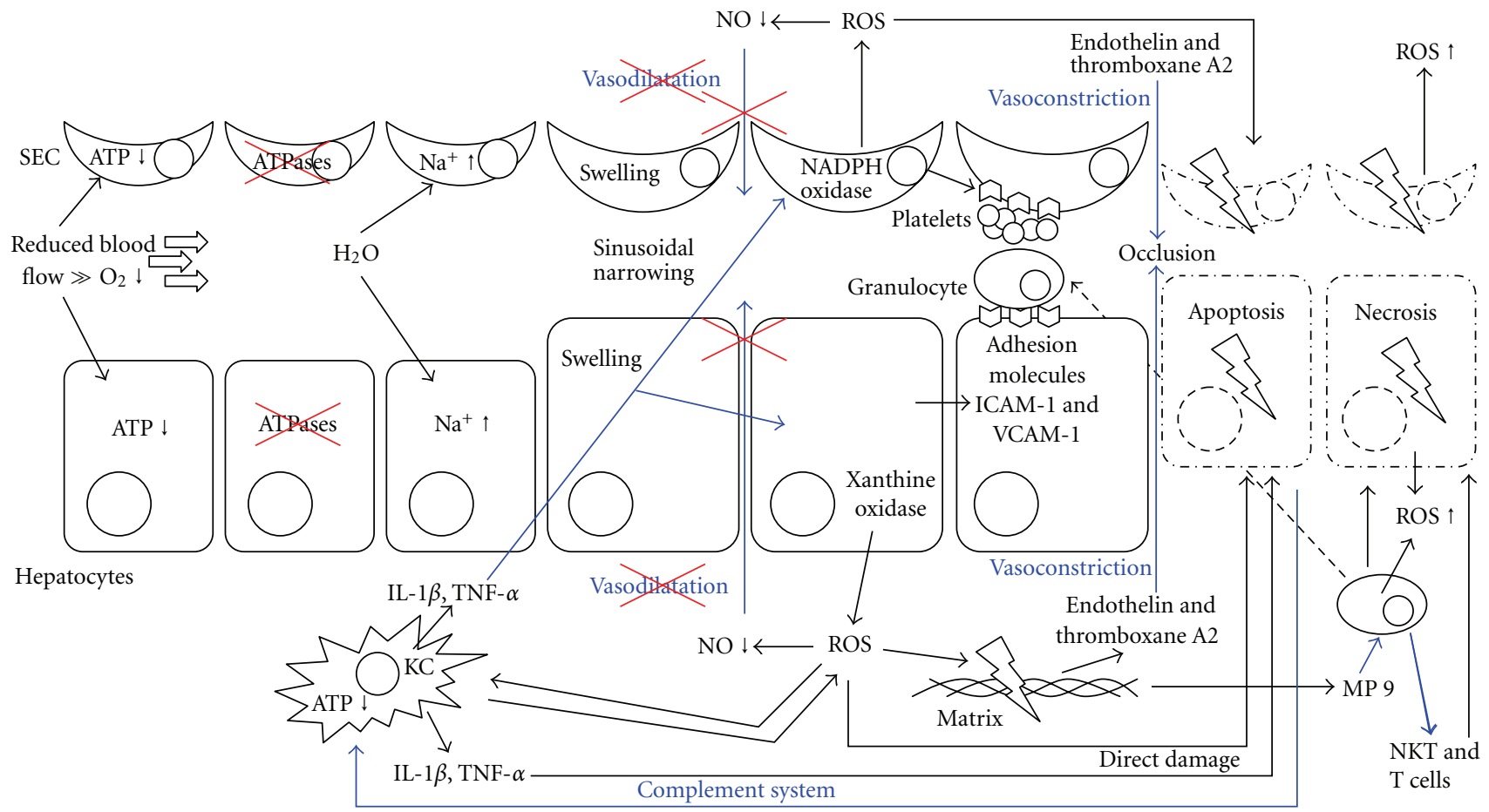

$\longrightarrow$ Leads to/induces

FIGURE 2: Cellular interaction involved in IR injury, resulting in cellular swelling, apoptosis, and necrosis. ATP: adenosine triphosphate; ICAM-1: intercellular adhesion molecule-1; KC: Kupffer cell; IL-1, interleukin-1; NKT: natural killer T cell; NO: nitric oxide; ROS: reactive oxygen species; SEC: sinusoidal endothelial cells; T cell: CD4+ T lymphocyte; TNF: tumor necrosis factor; VCAM-1: vascular adhesion molecule-1.

9 [67] after ischemic damage of the liver. Via production of interferon- $\gamma$ (IFN- $\gamma$ ) and IL-17 by activated CD4+ T lymphocytes additional activation of $\mathrm{KC}$ and hepatocytes is achieved $[68,69]$. Thus CD4+ T lymphocytes and $\mathrm{KC}$ reciprocally activate each other [64]. These chemokines furthermore activate natural killer T (NKT) cells. Activated NKT cells directly damage liver tissue and also produce IFN$\gamma$ with further activation of $\mathrm{KC}$ and hepatocytes $[69,70]$. The net result of this circular activation and stimulation of different cell sub types is destruction of hepatocytes and SEC $[71,72]$.

The expressed cell-surface adhesion molecules on hepatocytes and SEC include intercellular adhesion molecule1 (ICAM-1) and vascular adhesion molecule-1 (VCAM-1) $[28,73]$. Neutrophils bind to ICAM-1 and VCAM-1 and by doing so migrate across the endothelium into the liver parenchyma enhancing ROS production and degranulation of cytoplasmic vesicles containing enzymes capable to degrade extracellular matrix and hepatocytes [28] (Figure 2).

\section{Death Signalling Pathways}

Besides direct damage of hepatocytes by neutrophils, NKT cells, the complement system and ROS, the main destruction of cells is mediated by endogeneous pathways leading to apoptosis or necrosis of hepatic cells during IR injury.

This paper is not capable to focus on all cytokine cascades with pro- and antiinflammatory effects [74] as well as their effect during IR injury, but will concentrate on some important signalling pathways. The most important component in IR injury seems to be TNF- $\alpha[75,76]$. The pathways leading to up regulation of TNF- $\alpha$ have been described above. TNF$\alpha$ binds to specific TNF-receptors, as for example TNFR1 and TNF-R2, on the hepatocyte surface which leads to increased production of cytokines and ROS. In addition, activation of CD95 leads to apoptosis [77-79]. Furthermore, CD95 also binds NKT cells leading to direct destruction of hepatocytes [80].

Furthermore, downstream of the receptor the nuclear factor kappa B $(\mathrm{NF}-\kappa \mathrm{B})$, the mitogen-activated protein kinase (MAPK) and c-Jun N-terminal kinase (JNK) are activated [81-83]. The various cytokines and the mentioned molecules lead to alteration of various factors further downstream like transcription factors, activator protein-1 (AP-1), heat shock factor, signal transducer and activators of transcription (STATs), antioxidants, inflammationstimulated inducible enzymes (COX-2), intracellular signalling molecules, antiapoptotic proteins ( $\mathrm{Bcl}-2, \mathrm{Bcl}-\mathrm{x})$, and 
many more [37]. The damage in IR injury therefore spreads throughout the entire cell. NF- $\kappa \mathrm{B}$ furthermore upregulates the expression of cytokines, like TNF- $\alpha$ [84], and of ICAM1 and VCAM-1 [75, 82], enhancing the recruitment of neutrophils. AP-1 promotes apoptosis of liver cells by activation of caspase-3 and release of cytochrome C [82].

ROS furthermore inherit a direct oxidative damage of DNA within the nucleus resulting in further failure of protein transcription and translation. In addition, ROS cause posttranslational protein modification [85]. These alterations and pathways lead to apoptosis of the damaged cells.

The intracellular damage and alterations as well as the damage of extracellular matrix are followed by the release of danger-associated molecular patterns (DAMPs). Examples of DAMPs released during IR injury are the nuclear transcription factor high mobility group box-1 (HMGB-1), the cytoplasmic $\mathrm{Ca}^{2+}$ regulator S100, ATP, DNA, and hyaluronic acid [86-90]. DAMPs bind to a group of so-called pattern recognition receptors (PRRs) on the cell surface as well as in the cytoplasm [37]. In IR injury mainly two PRRs are involved, the toll-like receptors (TLRs), specifically TLR4 , and the receptor for advanced glycation end products (RAGE). To present knowledge TLR-4 provides an important link between liver damage and activation of the immune system. Activation of TLR-4 triggers intracellular signalling cascades in IR injury [91]. The Toll-IL-1 receptor domain (TIR) of TLR-4 interacts with intracellular adaptors. One may be the myeloid differentiation factor 88 (MyD88), others are TIR domain-containing adaptor inducing interferon- $\beta$ (TRIF), and TRIF-related adaptor molecule (TRAM) [92]. Via production of proinflammatory cytokines the inflammatory response is mediated leading to liver IR injury [9193]. Included in the downstream process of these activation are further transcription factors like NF- $\kappa \mathrm{B}, \mathrm{AP}-1$, STAT, the MAP kinase JNK, and ROS [86, 94-96].

The best characterized DAMP is HMGB-1 which is expressed by all nucleated cells within the liver and is released upon necrosis and apoptosis [86, 97]. HMGB-1 binding to RAGE in IR injury leads to a signalling cascade involving activation of JNK and other kinases, increasing expression and activation of the inducible transcription factor early growth response-1. As a consequence the upregulation of several gene families is found, recruiting immune cells into the post ischemic liver [98]. RAGE is mainly expressed on dendritic cells and to lesser extent on KC [98]. Furthermore, dendritic cells and KC also express TLR-4 [99]. This hints to an important, but at present unclear, function of dendritic cells during IR injury of the liver.

This complex communication of the described networks is responsible to initiate and propagate IR injury.

\section{Conclusions}

The understanding of the molecular mechanisms underlying cell death in hepatic IR injury will provide the basis for the development of new strategies for inhibition of liver injury and improvement of survival of the graft. The initial phase of IR injury involves the release of ROS and proinflammatory mediators by KC. ROS lead to oxidative damage, induction of p53, apoptosis and necrosis of hepatocytes and endothelial cells. The late phase (6-48 hours after reperfusion) is characterized by neutrophil-mediated inflammatory responses. Thus, proteins regulating the cellular redox equilibrium, p53-dependent apoptosis and cellular death receptors represent potential targets for novel pharmaceutical interventions to protect hepatocytes from IR injury-induced cell death.

\section{Author's Contribution}

Peter Schemmer and Martina Müller equally contributed to this work.

\section{References}

[1] H. de Groot and U. Rauen, "Ischemia-reperfusion injury: processes in pathogenetic networks: a review," Transplantation Proceedings, vol. 39, no. 2, pp. 481-484, 2007.

[2] Y. I. Kim, "Ischemia-reperfusion injury of the human liver during hepatic resection," Journal of Hepato-Biliary-Pancreatic Surgery, vol. 10, no. 3, pp. 195-199, 2003.

[3] G. D. Rushing and L. D. Britt, "Reperfusion injury after hemorrhage: a collective review," Annals of Surgery, vol. 247, no. 6, pp. 929-937, 2008.

[4] R. Birrer, Y. Takuda, and T. Takara, "Hypoxic hepatopathy: pathophysiology and prognosis," Internal Medicine, vol. 46, no. 14, pp. 1063-1070, 2007.

[5] A. Nickkholgh, M. Barro-Bejarano, R. Liang et al., "Signs of reperfusion injury following $\mathrm{CO}_{2}$ pneumoperitoneum: an in vivo microscopy study," Surgical Endoscopy and Other Interventional Techniques, vol. 22, no. 1, pp. 122-128, 2008.

[6] J. W. Kupiec-Weglinski and R. W. Busuttil, "Ischemia and reperfusion injury in liver transplantation," Transplantation Proceedings, vol. 37, no. 4, pp. 1653-1656, 2005.

[7] R. Liang, H. Bruns, M. Kincius et al., "Danshen protects liver grafts from ischemia/reperfusion injury in experimental liver transplantation in rats," Transplant International, vol. 22, no. 11, pp. 1100-1109, 2009.

[8] C. Fan, R. M. Zwacka, and J. F. Engelhardt, "Therapeutic approaches for ischemia/reperfusion injury in the liver," Journal of Molecular Medicine, vol. 77, no. 8, pp. 577-592, 1999.

[9] R. M. Zwacka, W. Zhou, Y. Zhang et al., "Redox gene therapy for ischemia/reperfusion injury of the liver reduces AP1 and NF- $\kappa$ B activation," Nature Medicine, vol. 4, no. 6, pp. 698-704, 1998.

[10] C. C. Caldwell, T. Okaya, A. Martignoni, T. Husted, R. Schuster, and A. B. Lentsch, "Divergent functions of $\mathrm{CD}^{+}$ $\mathrm{T}$ lymphocytes in acute liver inflammation and injury after ischemia-reperfusion," American Journal of Physiology, vol. 289, no. 5, pp. G969-G976, 2005.

[11] I. N. Hines, J. M. Hoffman, H. Scheerens et al., "Regulation of postischemic liver injury following different durations of ischemia," American Journal of Physiology, vol. 284, no. 3, pp. G536-G545, 2003.

[12] T. L. Husted and A. B. Lentsch, "The role of cytokines in pharmacological modulation of hepatic ischemia/reperfusion injury," Current Pharmaceutical Design, vol. 12, no. 23, pp. 2867-2873, 2006.

[13] J. K. Pine, A. Aldouri, A. L. Young et al., "Liver transplantation following donation after cardiac death: an analysis using matched pairs," Liver Transplantation, vol. 15, no. 9, pp. 10721082, 2009. 
[14] D. Takeuchi, H. Yoshidome, H. Kurosawa et al., "Interleukin18 exacerbates pulmonary injury after hepatic ischemia/reperfusion in mice," Journal of Surgical Research, vol. 158, no. 1, pp. 87-93, 2010.

[15] A. A. Weinbroum, A. Kidron, E. Hochhauser, A. Hochman, V. Rudick, and B. A. Vidne, "Liver glutathione level influences myocardial reperfusion injury following liver ischemiareperfusion," Medical Science Monitor, vol. 7, no. 6, pp. 1137$1144,2001$.

[16] M. Behrends, R. Hirose, Y. H. Park et al., "Remote renal injury following partial hepatic ischemia/reperfusion injury in rats," Journal of Gastrointestinal Surgery, vol. 12, no. 3, pp. 490-495, 2008.

[17] A. A. Weinbroum, "N-acetyl-L-cysteine mitigates aortic tone injury following liver ischemia-reperfusion," Journal of Cardiovascular Pharmacology, vol. 45, no. 6, pp. 509-515, 2005.

[18] T. Okaya, J. Blanchard, R. Schuster et al., "Age-dependent responses to hepatic ischemia/reperfusion injury," Shock, vol. 24, no. 5, pp. 421-427, 2005.

[19] Y. Yokoyama, M. Nagino, and Y. Nimura, "Which gender is better positioned in the process of liver surgery? Male or female?" Surgery Today, vol. 37, no. 10, pp. 823-830, 2007.

[20] S. Manekeller, M. Sioutis, A. Hirner, and T. Minor, "Influence of neoadjuvant chemotherapy on liver integrity and ischemic tolerance," Zeitschrift fur Gastroenterologie, vol. 46, no. 1, pp. 17-21, 2008.

[21] P. Schemmer, A. Nickkholgh, U. Hinz et al., "Extended donor criteria have no negative impact on early outcome after liver transplantation: a single-center multivariate analysis," Transplantation Proceedings, vol. 39, no. 2, pp. 529-534, 2007.

[22] B. Vollmar and M. D. Menger, "Intestinal ischemia/reperfusion: microcirculatory pathology and functional consequences," Langenbeck's Archives of Surgery, vol. 396, no. 1, pp. 13-29, 2011.

[23] G. Schindler, M. Kincius, R. Liang et al., "Fundamental efforts toward the development of a therapeutic cocktail with a manifold ameliorative effect on hepatic ischemia/reperfusion injury," Microcirculation, vol. 16, no. 7, pp. 593-602, 2009.

[24] Z. Zhong, H. D. Connor, M. Froh et al., "Free radicaldependent dysfunction of small-for-size rat liver grafts: prevention by plant polyphenols," Gastroenterology, vol. 129, no. 2, pp. 652-664, 2005.

[25] C. Eipel, K. Abshagen, and B. Vollmar, "Regulation of hepatic blood flow: the hepatic arterial buffer response revisited," World Journal of Gastroenterology, vol. 16, no. 48, pp. 60466057, 2010.

[26] M. Seizner, N. Seizmer, W. Jochum, R. Graf, and P. A. Clavien, "Increased ischemic injury in old mouse liver: an ATPdependent mechanism," Liver Transplantation, vol. 13, no. 3, pp. 382-390, 2007.

[27] M. Froh, M. D. Wheeler, O. Smutney, Z. Zhong, B. U. Bradford, and R. G. Thurman, "New method of delivering gene-altered Kupffer cells to rat liver: studies in an ischemiareperfusion model," Gastroenterology, vol. 124, no. 1, pp. 172183, 2003.

[28] H. Jaeschke, "Mechanisms of liver injury. II. Mechanisms of neutrophil-induced liver cell injury during hepatic ischemiareperfusion and other acute inflammatory conditions," American Journal of Physiology, vol. 290, no. 6, pp. G1083-G1088, 2006.

[29] A. M. Lefer and D. J. Lefer, "II. Nitric oxide protects in intestinal inflammation," American Journal of Physiology, vol. 276, no. 3, pp. G572-G575, 1999.
[30] M. B. Grisham, D. N. Granger, and D. J. Lefer, "Modulation of leukocyte-endothelial interactions by reactive metabolites of oxygen and nitrogen: relevance to ischemic heart disease," Free Radical Biology and Medicine, vol. 25, no. 4-5, pp. 404433, 1998.

[31] L. Phillips, A. H. Toledo, F. Lopez-Neblina, R. Anaya-Prado, and L. H. Toledo-Pereyra, "Nitric oxide mechanism of protection in ischemia and reperfusion injury," Journal of Investigative Surgery, vol. 22, no. 1, pp. 46-55, 2009.

[32] Y. Abe, I. Hines, G. Zibari, and M. B. Grisham, "Hepatocellular protection by nitric oxide or nitrite in ischemia and reperfusion injury," Archives of Biochemistry and Biophysics, vol. 484, no. 2, pp. 232-237, 2009.

[33] C. Contaldo, A. Elsherbiny, N. Lindenblatt et al., "Erythropoietin enhances oxygenation in critically perfused tissue through modulation of nitric oxide synthase," Shock, vol. 31, no. 6, pp. 599-606, 2009.

[34] M. Abu-Amara, S. Y. Yang, A. Seifalian, B. Davidson, and B. Fuller, "The nitric oxide pathway-evidence and mechanisms for protection against liver ischaemia reperfusion injury," Liver International, vol. 32, pp. 531-543, 2012.

[35] H. Jaeschke, "Role of reactive oxygen species in hepatic ischemia-reperfusion injury and preconditioning," Journal of Investigative Surgery, vol. 16, no. 3, pp. 127-140, 2003.

[36] H. Urakami, Y. Abe, and M. B. Grisham, "Role of reactive metabolites of oxygen and nitrogen in partial liver transplantation: lessons learned from reduced-size liver ischaemia and reperfusion injury," Clinical and Experimental Pharmacology and Physiology, vol. 34, no. 9, pp. 912-919, 2007.

[37] M. Abu-Amara, S. Y. Yang, N. Tapuria, B. Fuller, B. Davidson, and A. Seifalian, "Liver ischemia/reperfusion injury: processes in inflammatory networks-a review," Liver Transplantation, vol. 16, no. 9, pp. 1016-1032, 2010.

[38] E. E. Montalvo-Jave, T. Escalante-Tattersfield, J. A. OrtegaSalgado, E. Piña, and D. A. Geller, "Factors in the pathophysiology of the liver ischemia-reperfusion injury," Journal of Surgical Research, vol. 147, no. 1, pp. 153-159, 2008.

[39] A. Belous, C. Knox, I. B. Nicoud et al., "Reversed activity of mitochondrial adenine nucleotide translocator in ischemiareperfusion," Transplantation, vol. 75, no. 10, pp. 1717-1723, 2003.

[40] F. López-Neblina, L. H. Toledo-Pereyra, A. H. Toledo, and J. Walsh, "Ryanodine receptor antagonism protects the ischemic liver and modulates TNF- $\alpha$ and IL-10," Journal of Surgical Research, vol. 140, no. 1, pp. 121-128, 2007.

[41] B. A. Miller, "The role of TRP channels in oxidative stressinduced cell death," Journal of Membrane Biology, vol. 209, no. 1, pp. 31-41, 2006.

[42] N. Jiang, Z. M. Zhang, L. Liu, C. Zhang, Y. L. Zhang, and Z. C. Zhang, "Effects of $\mathrm{Ca}^{+}$channel blockers on store-operated $\mathrm{Ca}^{+}$channel currents of Kupffer cells after hepatic ischemia /reperfusion injury in rats," World Journal of Gastroenterology, vol. 12, no. 29, pp. 4694-4698, 2006.

[43] G. J. Barritt, J. Chen, and G. Y. Rychkov, "Ca2+ ${ }^{+}$-permeable channels in the hepatocyte plasma membrane and their roles in hepatocyte physiology," Biochimica et Biophysica Acta, vol. 1783, no. 5, pp. 651-672, 2008.

[44] P. K. Janicki, P. E. Wise, A. E. Belous, and C. W. Pinson, "Interspecies differences in hepatic $\mathrm{Ca}_{2}{ }^{+}$-ATPase activity and the effect of cold preservation on porcine liver Ca2 ${ }^{+}$-ATPase function," Liver Transplantation, vol. 7, no. 2, pp. 132-139, 2001.

[45] C. D. Anderson, J. Pierce, I. Nicoud, A. Belous, C. D. Knox, and R. S. Chari, "Modulation of mitochondrial calcium 
management attenuates hepatic warm ischemia-reperfusion injury," Liver Transplantation, vol. 11, no. 6, pp. 663-668, 2005.

[46] C. D. Knox, J. M. Pierce, I. B. Nicoud et al., "Inhibition of phospholipase $\mathrm{C}$ attenuates liver mitochondrial calcium overload following cold ischemia," Transplantation, vol. 81, no. 4, pp. 567-572, 2006.

[47] A. E. Belous, C. M. Jones, A. Wakata et al., "Mitochondrial calcium transport is regulated by $\mathrm{P} 2 \mathrm{Y} 1$ - and $\mathrm{P} 2 \mathrm{Y} 2$-like mitochondrial receptors," Journal of Cellular Biochemistry, vol. 99, no. 4, pp. 1165-1174, 2006.

[48] K. Zhao, G. M. Zhao, D. Wu et al., "Cell-permeable peptide antioxidants targeted to inner mitochondrial membrane inhibit mitochondrial swelling, oxidative cell death, and reperfusion injury," Journal of Biological Chemistry, vol. 279, no. 33, pp. 34682-34690, 2004.

[49] H. Jaeschke and J. J. Lemasters, "Apoptosis versus oncotic necrosis in hepatic ischemia/reperfusion injury," Gastroenterology, vol. 125, no. 4, pp. 1246-1257, 2003.

[50] D. B. Zorov, M. Juhaszova, Y. Yaniv, H. B. Nuss, S. Wang, and S. J. Sollott, "Regulation and pharmacology of the mitochondrial permeability transition pore," Cardiovascular Research, vol. 83, no. 2, pp. 213-225, 2009.

[51] J. J. Lemasters, T. P. Theruvath, Z. Zhong, and A. L. Nieminen, "Mitochondrial calcium and the permeability transition in cell death," Biochimica et Biophysica Acta, vol. 1787, no. 11, pp. 1395-1401, 2009.

[52] S. P. Elmore, T. Qian, S. F. Grissom, and J. J. Lemasters, "The mitochondrial permeability transition initiates autophagy in rat hepatocytes," The FASEB Journal, vol. 15, no. 12, pp. 22862287, 2001.

[53] I. Kim, S. Rodriguez-Enriquez, and J. J. Lemasters, "Selective degradation of mitochondria by mitophagy," Archives of Biochemistry and Biophysics, vol. 462, no. 2, pp. 245-253, 2007.

[54] J. S. Kim, T. Qian, and J. J. Lemasters, "Mitochondrial permeability transition in the switch from necrotic to apoptotic cell death in ischemic rat hepatocytes," Gastroenterology, vol. 124, no. 2, pp. 494-503, 2003.

[55] D. Wang, K. Dou, Z. Song, and Z. Liu, "The $\mathrm{Na}(+) / \mathrm{H}(+)$ exchange inhibitor: a new therapeutic approach for hepatic ischemia injury in rats," Transplantation Proceedings, vol. 35, no. 8, pp. 3134-3135, 2003.

[56] R. Carini, M. G. De Cesaris, R. Splendore, M. Bagnati, G. Bellomo, and E. Albano, "Alterations of $\mathrm{Na}+$ homeostasis in hepatocyte reoxygenation injury," Biochimica et Biophysica Acta, vol. 1500, no. 3, pp. 297-305, 2000.

[57] M. Vairetti, P. Richelmi, F. Bertè, R. T. Currin, J. J. Lemasters, and R. Imberti, "Role of $\mathrm{pH}$ in protection by low sodium against hypoxic injury in isolated perfused rat livers," Journal of Hepatology, vol. 44, no. 5, pp. 894-901, 2006.

[58] A. Caban, G. Oczkowicz, O. Abdel-Samad, and L. Cierpka, "Influence of Kupffer cells on the early phase of liver reperfusion," Transplantation Proceedings, vol. 34, no. 2, pp. 694-697, 2002.

[59] H. Bruns, I. Watanpour, M. M. Gebhard et al., "Glycine and taurine equally prevent fatty livers from Kupffer celldependent injury: an in Vivo microscopy study," Microcirculation, vol. 18, no. 3, pp. 205-213, 2011.

[60] P. Schemmer, R. Schoonhoven, J. A. Swenberg, H. Bunzendahl, and R. G. Thurman, "Gentle in situ liver manipulation during organ harvest decreases survival after rat liver transplantation: role of Kupffer cells," Transplantation, vol. 65, no. 8, pp. 10151020, 1998.

[61] R. W. Brock, R. G. Nie, K. A. Harris, and R. F. Potter, "Kupffer cell-initiated remote hepatic injury following bilateral hindlimb ischemia is complement dependent," American Journal of Physiology, vol. 280, no. 2, pp. G279-G284, 2001.

[62] C. Fondevila, X. D. Shen, S. Tsuchihashi et al., "The membrane attack complex (C5b-9) in liver cold ischemia and reperfusion injury," Liver Transplantation, vol. 14, no. 8, pp. 1133-1141, 2008.

[63] L. Llacuna, M. Marí, J. M. Lluis, C. García-Ruiz, J. C. Fernández-Checa, and A. Morales, "Reactive oxygen species mediate liver injury through parenchymal nuclear factor$\kappa \mathrm{B}$ inactivation in prolonged ischemia/reperfusion," American Journal of Pathology, vol. 174, no. 5, pp. 1776-1785, 2009.

[64] M. Hanschen, S. Zahler, F. Krombach, and A. Khandoga, "Reciprocal activation between $\mathrm{CD} 4^{+} \mathrm{T}$ cells and Kupffer cells during hepatic ischemia-reperfusion," Transplantation, vol. 86, no. 5, pp. 710-718, 2008.

[65] H. Taniai, I. N. Hines, S. Bharwani et al., "Susceptibility of murine periportal hepatocytes to hypoxia-reoxygenation: role for NO and Kupffer cell-derived oxidants," Hepatology, vol. 39, no. 6, pp. 1544-1552, 2004.

[66] Y. Nakano, T. Kondo, R. Matsuo et al., "Platelet dynamics in the early phase of postischemic liver in vivo," Journal of Surgical Research, vol. 149, no. 2, pp. 192-198, 2008.

[67] A. Khandoga, J. S. Kessler, M. Hanschen et al., "Matrix metalloproteinase- 9 promotes neutrophil and $\mathrm{T}$ cell recruitment and migration in the postischemic liver," Journal of Leukocyte Biology, vol. 79, no. 6, pp. 1295-1305, 2006.

[68] C. C. Caldwell, J. Tschoep, and A. B. Lentsch, "Lymphocyte function during hepatic ischemia/reperfusion injury," Journal of Leukocyte Biology, vol. 82, no. 3, pp. 457-464, 2007.

[69] S. Kuboki, N. Sakai, J. Tschöp, M. J. Edwards, A. B. Lentsch, and C. C. Caldwell, "Distinct contributions of $\mathrm{CD} 4^{+} \mathrm{T}$ cell subsets in hepatic ischemia/reperfusion injury," American Journal of Physiology, vol. 296, no. 5, pp. G1054-G1059, 2009.

[70] C. M. Lappas, Y. J. Day, M. A. Marshall, V. H. Engelhard, and J. Linden, "Adenosine $\mathrm{A}_{2 \mathrm{~A}}$ receptor activation reduces hepatic ischemia reperfusion injury by inhibiting CD1d-dependent NKT cell activation," Journal of Experimental Medicine, vol. 203, no. 12, pp. 2639-2648, 2006.

[71] A. Khandoga, M. Hanschen, J. S. Kessler, and F. Krombach, "CD4 ${ }^{+} \mathrm{T}$ cells contribute to postischemic liver injury in mice by interacting with sinusoidal endothelium and platelets," Hepatology, vol. 43, no. 2, pp. 306-315, 2006.

[72] M. Froh, Z. Zhong, P. Walbrun et al., "Dietary glycine blunts liver injury after bile duct ligation in rats," World Journal of Gastroenterology, vol. 14, no. 39, pp. 5996-6003, 2008.

[73] N. Selzner, M. Selzner, B. Odermatt, Y. Tian, N. Van Rooijen, and P. A. Clavien, "ICAM-1 triggers liver regeneration through leukocyte recruitment and Kupffer cell-dependent release of TNF- $\alpha$ /IL-6 in mice," Gastroenterology, vol. 124, no. 3, pp. 692-700, 2003.

[74] O. Gressner, T. Schilling, K. Lorenz et al., "TAp63 $\alpha$ induces apoptosis by activating signaling via death receptors and mitochondria," EMBO Journal, vol. 24, no. 13, pp. 2458-2471, 2005.

[75] C. Peralta, L. Fernández, J. Panés et al., "Preconditioning protects against systemic disorders associated with hepatic ischemia-reperfusion through blockade of tumor necrosis factor-induced P-selectin up-regulation in the rat," Hepatology, vol. 33, no. 1, pp. 100-113, 2001.

[76] H. A. Rüdiger and P. Clavien, "Tumor necrosis factor $\alpha$, but not Fas, mediates hepatocellular apoptosis in the murine ischemic liver," Gastroenterology, vol. 122, no. 1, pp. 202-210, 2002. 
[77] M. Müller, S. Strand, H. Hug et al., "Drug-induced apoptosis in hepatoma cells is mediated by the CD95 (APO- $1 / \mathrm{Fas}$ ) receptor/ligand system and involves activation of wild-type p53," Journal of Clinical Investigation, vol. 99, no. 3, pp. 403413, 1997.

[78] M. Müller, S. Wilder, D. Bannasch et al., "p53 activates the CD95 (APO-1/Fas) gene in response to DNA damage by anticancer drugs," Journal of Experimental Medicine, vol. 188, no. 11, pp. 2033-2045, 1998.

[79] S. T. Eichhorst, M. Muller, M. Li-Weber, H. SchulzeBergkamen, P. Angel, and P. H. Krammer, "A novel AP-1 element in the CD95 ligand promoter is required for induction of apoptosis in hepatocellular carcinoma cells upon treatment with anticancer drugs," Molecular and Cellular Biology, vol. 20, no. 20, pp. 7826-7837, 2000.

[80] B. Li, B. Chen, G. Zhang, K. Wang, L. Zhou, and S. Hu, "Cell apoptosis and fas gene expression in liver and renal tissues after ischemia-reperfusion injury in liver transplantation," Transplantation Proceedings, vol. 42, no. 5, pp. 1550-1556, 2010.

[81] C. A. Bradham, P. Schemmer, R. F. Stachlewitz, R. G. Thurman, and D. A. Brenner, "Activation of nuclear factor$\kappa \mathrm{B}$ during orthotopic liver transplantation in rats is protective and does not require Kupffer cells," Liver Transplantation and Surgery, vol. 5, no. 4, pp. 282-293, 1999.

[82] R. F. Schwabe and D. A. Brenner, "Mechanisms of liver injury. I. TNF- $\alpha$-induced liver injury: role of IKK, JNK, and ROS pathways," American Journal of Physiology, vol. 290, no. 4, pp. G583-G589, 2006.

[83] R. Liang, A. Nickkholgh, K. Hoffmann et al., "Melatonin protects from hepatic reperfusion injury through inhibition of IKK and JNK pathways and modification of cell proliferation," Journal of Pineal Research, vol. 46, no. 1, pp. 8-14, 2009.

[84] S. Sanlioglu, C. M. Williams, L. Samavati et al., "Lipopolysaccharide induces Rac1-dependent reactive oxygen species formation and coordinates tumor necrosis factor- $\alpha$ secretion through IKK regulation of NF- $\kappa \mathrm{B}$," Journal of Biological Chemistry, vol. 276, no. 32, pp. 30188-30198, 2001.

[85] C. Szabó, H. Ischiropoulos, and R. Radi, "Peroxynitrite: biochemistry, pathophysiology and development of therapeutics," Nature Reviews Drug Discovery, vol. 6, no. 8, pp. 662-680, 2007.

[86] A. Tsung, R. Sahai, H. Tanaka et al., "The nuclear factor HMGB1 mediates hepatic injury after murine liver ischemiareperfusion," Journal of Experimental Medicine, vol. 201, no. 7, pp. 1135-1143, 2005.

[87] L. E. Pelinka, N. Harada, L. Szalay, M. Jafarmadar, H. Redl, and S. Bahrami, "Release of S100B differs during ischemia and reperfusion of the liver, the gut, and the kidney in rats.," Shock, vol. 21, no. 1, pp. 72-76, 2004.

[88] J. Zhang, H. Wang, Q. Xiao et al., "Hyaluronic acid fragments evoke Kupffer cells via TLR4 signaling pathway," Science in China C, vol. 52, no. 2, pp. 147-154, 2009.

[89] M. Pardo, N. Budick-Harmelin, B. Tirosh, and O. Tirosh, "Antioxidant defense in hepatic ischemia-reperfusion injury is regulated by damage-associated molecular pattern signal molecules," Free Radical Biology and Medicine, vol. 45, no. 8, pp. 1073-1083, 2008.

[90] Z. M. Bamboat, V. P. Balachandran, L. M. Ocuin, H. Obaid, G. Plitas, and R. P. DeMatteo, "Toll-like receptor 9 inhibition confers protection from liver ischemia-reperfusion injury," Hepatology, vol. 51, no. 2, pp. 621-632, 2010.

[91] A. Katsargyris, C. Klonaris, A. Alexandrou, A. E. Giakoustidis, I. Vasileiou, and S. Theocharis, "Toll like receptors in liver ischemia reperfusion injury: a novel target for therapeutic modulation?" Expert Opinion on Therapeutic Targets, vol. 13, no. 4, pp. 427-442, 2009.

[92] T. V. Arumugam, E. Okun, S. C. Tang, J. Thundyil, S. M. Taylor, and T. M. Woodruff, "Toll-like receptors in ischemiareperfusion injury," Shock, vol. 32, no. 1, pp. 4-16, 2009.

[93] G. Szabo, A. Dolganiuc, and P. Mandrekar, "Pattern recognition receptors: a contemporary view on liver diseases," Hepatology, vol. 44, no. 2, pp. 287-298, 2006.

[94] S. I. Tsuchihashi, Y. Zhai, Q. Bo, R. W. Busuttil, and J. W. Kupiec-Weglinski, "Heme oxygenase-1 mediated cytoprotection against liver ischemia and reperfusion injury: inhibition of type-1 interferon signaling," Transplantation, vol. 83, no. 12, pp. 1628-1634, 2007.

[95] H. Wang, Z. Y. Li, H. S. Wu et al., "Endogenous danger signals trigger hepatic ischemia/reperfusion injury through toll-like receptor 4/nuclear factor-kappa B pathway," Chinese Medical Journal, vol. 120, no. 6, pp. 509-514, 2007.

[96] Y. Zhai, X. D. Shen, R. O’Connell et al., "Cutting edge: TLR4 activation mediates liver ischemia/reperfusion inflammatory response via IFN regulatory factor 3-dependent MyD88independent pathway," Journal of Immunology, vol. 173, no. 12, pp. 7115-7119, 2004.

[97] T. Watanabe, S. Kubota, M. Nagaya et al., "The role of HMGB1 on the development of necrosis during hepatic ischemia and hepatic ischemia/reperfusion injury in mice," Journal of Surgical Research, vol. 124, no. 1, pp. 59-66, 2005.

[98] S. Zeng, H. Dun, N. Ippagunta et al., "Receptor for advanced glycation end product (RAGE)-dependent modulation of early growth response-1 in hepatic ischemia/reperfusion injury," Journal of Hepatology, vol. 50, no. 5, pp. 929-936, 2009.

[99] A. Tsung, N. Zheng, G. Jeyabalan et al., "Increasing numbers of hepatic dendritic cells promote HMGB1-mediated ischemiareperfusion injury," Journal of Leukocyte Biology, vol. 81, no. 1, pp. 119-128, 2007. 


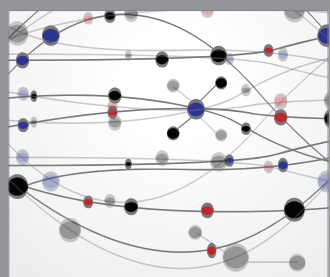

The Scientific World Journal
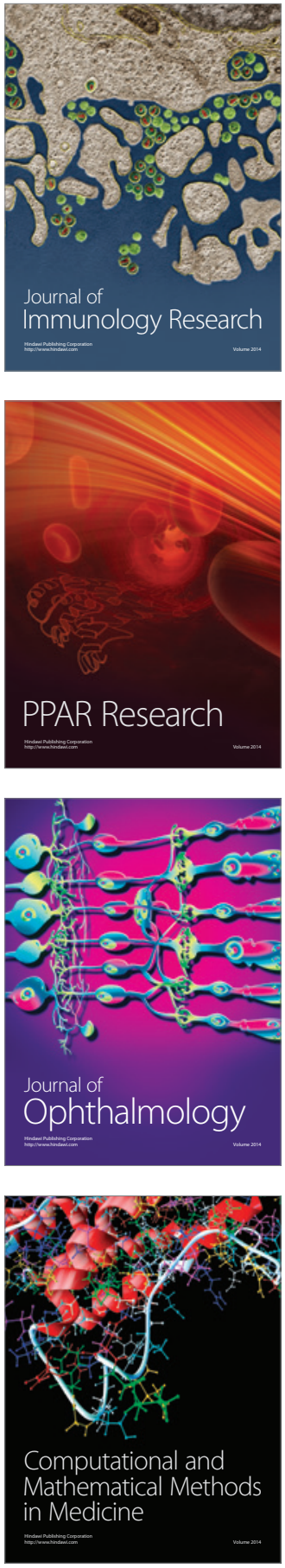

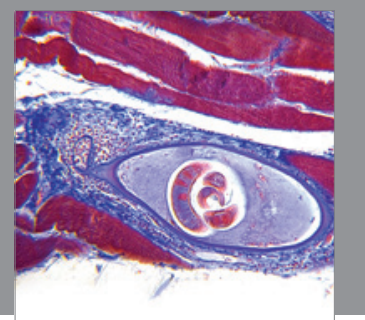

Gastroenterology

Research and Practice
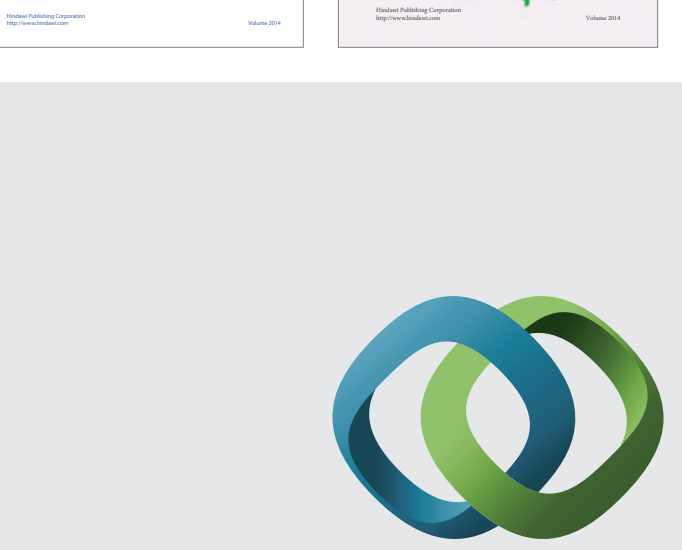

\section{Hindawi}

Submit your manuscripts at

http://www.hindawi.com
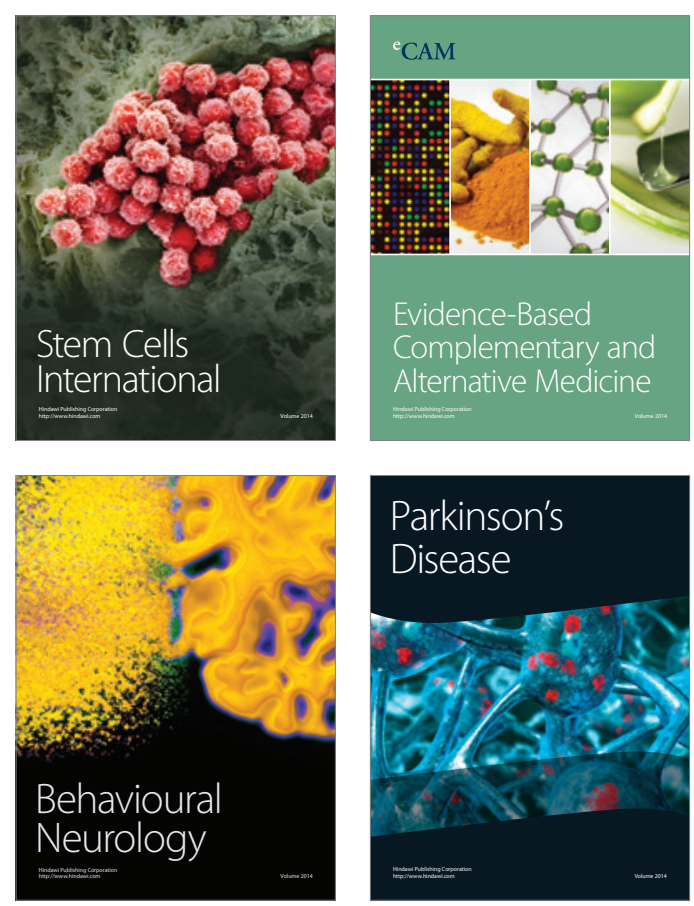

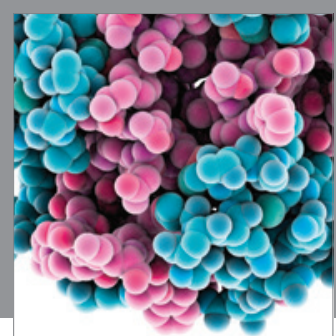

Journal of
Diabetes Research

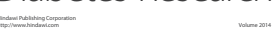

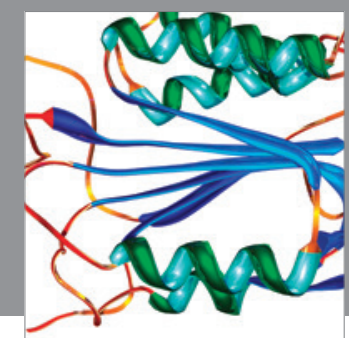

Disease Markers
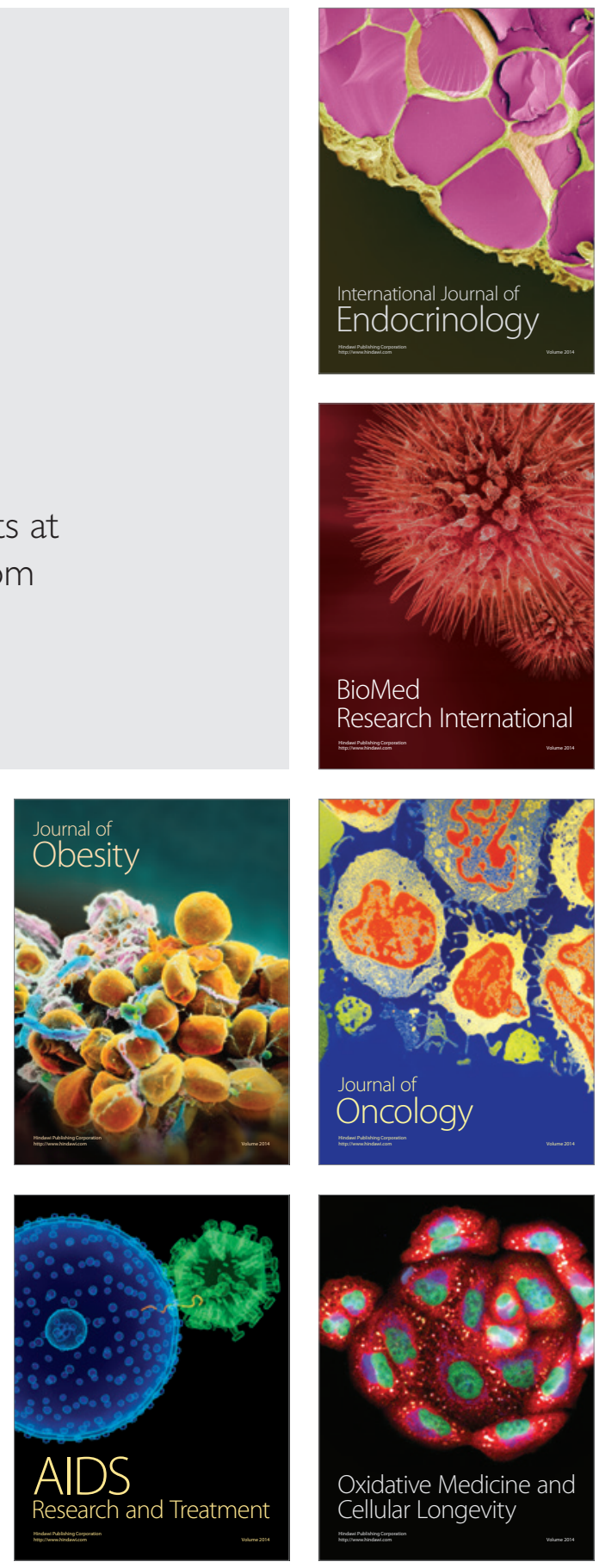